\title{
Self-care Barriers Reported by Emergency Department Patients With Acute Heart Failure: A Sociotechnical Systems-based Approach
}

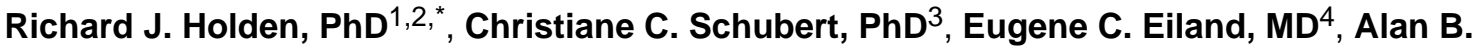 \\ Storrow, MD ${ }^{4}$, Karen F. Miller, MPA ${ }^{4}$, and Sean P. Collins, MD, MSc ${ }^{4}$ \\ ${ }^{1}$ Department of BioHealth, Indiana University School of Informatics and Computing, Indianapolis, \\ IN, USA \\ ${ }^{2}$ Center for Health Informatics Research and Innovation (CHIRI), Indianapolis, IN, USA \\ ${ }^{3}$ Department of Medical Education, Loma Linda University School of Medicine, Loma Linda, CA, \\ USA \\ ${ }^{4}$ Department of Emergency Medicine, Vanderbilt University School of Medicine, Nashville, TN, \\ USA
}

\begin{abstract}
Objective-To pilot a sociotechnical systems-based instrument that assesses the prevalence and nature of self-care barriers among patients presenting to the emergency department (ED) with acute heart failure.

Methods-A semi-structured instrument for measuring self-reported self-care barriers was developed and administered by ED clinicians and non-clinician researchers to $31 \mathrm{ED}$ patients diagnosed with acute heart failure. Responses were analyzed using descriptive statistics and qualitative content analysis. Feasibility was assessed by examining participant cooperation rates, instrument completion times, item nonresponse, and data yield.
\end{abstract}

Results-Of 47 distinct self-care barriers assessed, a median of 15 per patient were indicated as "sometimes" or "often" present. Thirty-four specific barriers were reported by over $25 \%$ of patients and nine were reported by over $50 \%$. The sources of barriers included the person, self-

\footnotetext{
(C) 2014 by the American College of Emergency Physicians. All rights reserved.

*Corresponding author: Richard J. Holden, Walker Plaza - WK319, 719 Indiana Avenue, Indianapolis, IN 46202, USA. (ph) 1-317-278-5323, rjholden@iupui.edu..

Publisher's Disclaimer: This is a PDF file of an unedited manuscript that has been accepted for publication. As a service to our customers we are providing this early version of the manuscript. The manuscript will undergo copyediting, typesetting, and review of the resulting proof before it is published in its final citable form. Please note that during the production process errors may be discovered which could affect the content, and all legal disclaimers that apply to the journal pertain.

Conflicts of interest: None to declare.

Meetings: A poster was presented halfway through the project at the Human Factors and Ergonomics Society (HFES) Healthcare Symposium, March 2014, Chicago, IL. No proceedings paper or abstract was published about this poster.

Author contributions: RJH, CCS, ABS, and SPC conceived and designed the study. RJH obtained research funding, developed and reviewed the analysis, drafted the manuscript, and takes responsibility for the paper as a whole. All authors collected data and contributed to the manuscript. CCS and SPC conducted and reported on parts of the analysis. SPC and KFM supervised enrollment and data collection activities.
} 
care tasks, tools and technologies, and organizational, social, and physical contexts. Seven of the top ten most prevalent barriers were related to patient characteristics and the next three to the organizational context (e.g., life disruptions). A preliminary feasibility assessment found few item nonresponses or comprehension difficulties, good cooperation, high data yield from both closedand open-ended items, but opportunities to reduce median administration time and variability.

Conclusions-An instrument assessing self-care barriers from multiple system sources can be feasibly implemented in the ED. Further research is required to modify the instrument for widespread use and evaluate its implementation across institutions and cultural contexts. Self-care barriers measurement can be one component of broader inquiry into the distributed health-related "work" activity of patients, caregivers, and clinicians.

\section{Keywords}

acute heart failure; self-care barriers; sociotechnical systems model; mixed methods

\section{INTRODUCTION}

\subsection{Background}

Acute heart failure (AHF) is a major and potentially modifiable cause of US healthcare expenditures. ${ }^{1}$ Patients with AHF typically seek emergency department (ED) care and $80 \%$ of these are subsequently admitted to an inpatient setting. ${ }^{2}$ While approximately $20 \%$ are diagnosed with de novo heart failure, most are experiencing an acute exacerbation of chronic heart failure. ${ }^{3}$ For these patients, AHF related hospitalizations represent the largest proportion of their annual healthcare expenditures. ${ }^{1,4}$ National estimates of heart failure 30day readmission rates exceed $20 \%$; heart failure is the top reason for readmission in Medicare patients. 5,6

A majority of AHF exacerbations result not only from physiological disease progression, but also due to challenges in self-care, particularly medication and dietary non-adherence. ${ }^{7-9}$ Self-care non-adherence is believed to occur in part due to a variety of barriers such as knowledge limitations, lack of social support, regimen complexity, and access to or cost of therapy. ${ }^{10-12}$ If barriers to self-care can be systematically identified and addressed alongside physiological risk, it may be possible to reduce AHF presentations, hospitalizations, and associated costs. ${ }^{8}$

Identifying and addressing self-care barriers in the ED is desirable because patients may have: 1) insufficient outpatient care support; 2) lack of motivation to address the issues prior to their ED visit; and 3) needs that can be immediately addressed by ED providers, ancillary staff such as social workers and case managers, or through outpatient referral prior to ED discharge. ${ }^{13,14}$

A recent qualitative study of 28 patients readmitted within 180 days of discharge after an AHF diagnosis found multiple self-reported reasons for readmission including financial difficulties, suboptimal healthcare delivery, and undesirable effects of medications. ${ }^{15}$ The authors urged further research with patients about their experienced challenges and a "shift from individual blame toward an empowerment and systems approach that considers the big 
picture". Accordingly, the present study uses a patient-centered, sociotechnical systems model to assess barriers to heart failure self-care in a sample of patients with AHF presenting to the ED.

Human factors engineering ${ }^{16,17}$ is a discipline whose sociotechnical systems-based approach has been productively used to understand and improve clinician performance, particularly in the ED. ${ }^{18-21}$ Recent work suggests this approach can also be valuable for understanding patient and lay caregiver performance of activities such as self-care. ${ }^{22-24}$ Figure 1 shows a sociotechnical systems model of self-care barriers among AHF patients. Drawing on prior human factors engineering models, ${ }^{16,23-25}$ it depicts barriers as products of multiple patient, task, technology, and contextual (or environmental) factors. ${ }^{26,27}$ Several reviews and comprehensive interview-based studies have identified barriers across these system components, but no study in heart failure has used a systems model. ${ }^{10,11,28-31}$ Furthermore, with few exceptions, ${ }^{14,32}$ heart failure self-care barriers have not been investigated during an acute exacerbation in the ED.

In parallel to the above work on sociotechnical systems, there has been a growing emphasis on capturing social determinants of health or contextual factors such as poverty and lack of transportation. ${ }^{33}$ It has been argued that the failure to consider these factors in planning or evaluating care constitutes a "contextual error" 34 that results in poorer outcomes. ${ }^{35}$ Furthermore, in 2014 the Institute of Medicine (IOM) released two reports recommending the use of structured instruments to measure and capture these contextual factors in electronic health records (EHR). ${ }^{36,37}$

\subsection{Goals of this investigation}

Our study objectives were to: (1) pilot a sociotechnical systems-based instrument to assess the prevalence and nature of barriers among patients presenting to the ED with AHF; and (2) conduct a preliminary feasibility assessment of this instrument in the time-sensitive ED setting.

\section{METHODS}

A semi-structured instrument for measuring self-reported self-care barriers was developed and administered to ED patients diagnosed with AHF. The study was approved by the Vanderbilt University Institutional Review Board (IRB).

\subsection{Setting}

This study was performed in the ED at Vanderbilt University Medical Center in Nashville, TN. The ED's census is approximately 70,000 annually, with 700 annual AHF admissions. While most participants were interviewed in the ED, seven were interviewed in a hospital unit.

\subsection{Selection of participants}

Adult ED patients were recruited using convenience sampling over an eight-month period between June 2013 and January 2014. A target of 30 participants was established based on resources available for this pilot study. Patients were approached if they were given a 
primary diagnosis of and treated for AHF by the ED physician. Inclusion criteria were being aged $\geq 18 \mathrm{y}$, having presented to the $\mathrm{ED}$ within $24 \mathrm{~h}$, and verification of a primary diagnosis of AHF by EHR or the treating ED physician. Patients were excluded if they were unable or unwilling to perform the interview. Patients' family members were consented if they showed interest in assisting patients' responses.

\subsection{Methods and measurement}

The instrument used self-report to assess the presence and nature of barriers stemming from an array of sociotechnical system factors (Figure 1). All authors, including three ED physicians (two attending, one resident) and two non-clinician researchers (one human factors engineer, one social scientist), reviewed the literature and suggested for the instrument barriers identified in clinical guidelines ${ }^{38-42}$ or across multiple systematic reviews and individual articles. ${ }^{10,15,29,31,43-55}$ A few less commonly reported barriers were added because they were identified in the research team's concurrent study of chronic heart failure patients. ${ }^{26,27}$ One item per barrier was developed, using literacy-appropriate wording based on questionnaires and barrier definitions. Several meetings were held to iterate the instrument. Following internal review and instrument testing with five participants, two items were eliminated due to redundancy and two reworded. The final instrument had 47 structured barrier items. The assessed barriers and precise item wording and order are reported in Appendix A. For each of the barriers, labeled "challenges" in the instrument, participants indicated whether it "often," "sometimes," or "never" "makes it harder to take good care of myself." These verbal qualifiers are commonly used for categorical response scales and have been found to have stable and proportional psychological distance from one another. ${ }^{56,57}$

The instrument also contained three types of open-ended probes:

- An opening probe inviting patients to self-report any self-care barriers prior to answering specific barrier items;

- A closing probe eliciting any additional information;

- Follow-up probes (“Tell me more about that..."), asked after any "often" or "sometimes" response to structured barrier items.

Patients were consented and interviewed by either an attending ED physician (ABS, SPC), ED resident (ECE), or a nonclinical researcher (RJH, CCS). The instrument was administered verbally, with the researcher hand-recording answers. Participants wishing to read along were given paper copies of the instrument. Participants were prompted to think about "challenges that you experience taking care of your health," with challenges defined as "things that make it harder to take good care of yourself.", This definition was reinforced by the response options (see Appendix A). Participants were first asked the opening probe and encouraged to give complete answers using nondirective language (e.g., "Okay, what else...?"). This was followed by asking the 47 closed-ended questions about specific barriers and follow-up probes to elicit further information about any barrier marked "sometimes" or

*The term "challenges" rather than "barriers" was used to because interviews showed that patients sometimes interpret barriers as physical obstacles and to reduce social desirability bias associated with negatively valenced terms. 
"often." Six additional closed-ended questions were asked about self-care facilitators but are not examined here. The interview concluded with the closing probe. Participants were not compensated.

After the interview, a clinician researcher reviewed the patient's medical record and collected demographics, past medical history, diagnoses, and laboratory results.

\subsection{Analysis}

Data were entered and maintained in a secure REDCap database. Quantitative analyses were carried out in SPSS v.22 (IBM Corp.). To address the first objective, regarding self-care barrier prevalence and nature, we computed (1) the total and mean number of barriers reported as "never," "sometimes," and "often" being experienced by patients and (2) the proportion of respondents responding "never," "sometimes," and "often" to each barrier item. We also dichotomized responses into "never" and "ever" ("sometimes" and "often") and computed totals, means, and proportions on the dichotomized scores. We carried out qualitative descriptive analysis ${ }^{58}$ of volunteered explanations and responses to the openended probes to produce a general understanding of each barrier, identify key barriers and barrier-barrier interactions in individual patients, and select illustrative examples. Qualitative description, or conventional content analysis, ${ }^{59}$ is an approach to describing verbal data that needs no prior structure (or coding framework) nor aims to create new theory. We hypothesized: 1) (H1a) multiple barriers would be reported per patient; 2) (H1b) patients would differ in their key barriers; 3) (H1c) across the sample, patient, task, tool, and context barriers would all be represented; and 4) (H1d) barriers related to individual, task, and social context factors would be especially prominent.

To address the second objective, regarding instrument feasibility in the ED, we calculated participant cooperation rates, instrument completion times, and item nonresponse. We also compared the amount and variety of information yielded using the full instrument versus responses to the opening/closing probes only, the latter resembling the kind of questions asked in standard ED practice (e.g., "Tell me what's going on... Anything else?"). These data and researchers' anecdotal experiences were combined for preliminary, descriptive feasibility assessment. We hypothesized: 1) (H2a) the instrument would yield value but 2) $(\mathrm{H} 2 \mathrm{~b})$ its administration would require streamlining to be integrated into ED practice.

\section{RESULTS}

\subsection{Characteristics of study participants}

A total of 31 patients participated, described in Table 1. Of these, 30 were admitted to hospital and only one was discharged to home. Fewer than $15 \%$ of those approached declined to participate.

A median of 15 out of 47 maximum possible barriers were reported by participants as "ever" being present (mean=16.29, $\mathrm{SD}=8.8$, range 2-38). As shown in Figure 2, barriers were rated as "sometimes" (median=11, M=9.93, $\mathrm{SD}=4.8$ ) more than "often" (median=5, $\mathrm{M}=6.35$, $\mathrm{SD}=5.3$ ) and there was a linear relationship between the number of barriers reported as occurring "sometimes" and "often" ( $\mathrm{r}=0.53, \mathrm{p} \leq .05)$. 
Table 2 reports the prevalence of self-care barriers. Thirty-four of the barriers were reported as ever occurring in $>25 \%$ of participants and nine barriers in $>50 \%$. Among the ten most prevalent barriers, the top seven were related to patient characteristics and the next three to the organizational context. There were several prevalent task-related barriers but tool-related barriers were infrequently reported. Weather and physical obstacles were frequently reported barriers related to the physical context and a food culture incompatible with dietary restrictions was the top barrier related to social context. Table $\mathbf{3}$ gives paraphrased and verbatim examples of specific barriers described by participants.

Of note, in many cases a participant had multiple self-care barriers (see Figure 2) and these were sometimes related or interacted. Figure 3 shows a barrier profile for one such case, a 52-year old black female with a tenth grade education and a recent incarceration who presented with localized edema after having delayed seeking treatment for about a month due to being uninsured. This individual describes multiple barriers across the different sociotechnical system categories and plotting these offers some insight into the distribution of barriers-in this case, a relatively even one, except for the absence of tool and technology barriers. Further, through the patient's responses to open-ended follow-up probes it is clear that some of the barriers interact:

- She is sick but is also taking care of others and working full time, making it hard to find time for self-care.

- She lives far from healthcare resources and lacks transportation, but does not like relying on others for help.

- Because of symptoms such as fatigue, it is difficult for her to perform work activities, but she cannot afford to quit her job.

- Her memory is declining and she reports having deficient knowledge and information about her self-care, but she does not use a pillbox; however, she does not regard the lack of pillbox as a barrier in and of itself.

Notably, patients' barrier profiles sometimes resembled the one in Figure 3 but at other times showed a different distribution of barriers. For example, there were two patients with significant social context barriers but no reported physical context barriers. Two others had relatively few organizational context barriers but reported having person-related barriers and a lack of tools.

With respect to feasibility, instrument administration lasted a median of 30 minutes and ranged from 20 to 90 minutes. Longer encounters were ones during which the participant had many barriers to probe or complicated explanations of their barriers; there was a modest correlation of $r=0.40$ between number of barriers reported and interview duration (though not taking into account interruptions). Durations were also longer with patients who had trouble concentrating. Reproduced below are abbreviated field notes following a 50-minute interview:

Patient had difficulties responding to the questions ... she was very slow and needed time to think. After 40 minutes, became restless, turning in bed as if difficult to get comfortable. Did not want to provide additional comments at the 
end of the interview and while she remained friendly clearly wanted to be left alone. Patient's chart shows diagnosis of bipolar disorder.

In $45 \%$ of cases, an informal caregiver was present during all or part of the encounter. Consenting caregivers sometimes helped to answer questions and fill in details, especially when the patient was less able (from fieldnotes: patient got very tired towards the end of the interview and her fiancé started to chime in more frequently).

There were very few item nonresponses, with an average of 0.39 items skipped or refused per participant (range 0-2 out of 45). Only one item (fitting self-care into the daily schedule) had more than one nonresponse across the 31 participants. Furthermore, most items yielded at least some responses of "sometimes" and "often." Only one (lack of "workspace" for selfcare tasks) yielded only "never" responses and four others (caregiver unavailability, resources for keeping appointments, low quality healthcare, tool overdependence) had $>85 \%$ responses of "never." Only four (13\%) participants had visible trouble comprehending item wording. Although the researcher always provided a written copy of the instrument, this was not always effective (from fieldnotes: reading questions with patient was a little difficult because he could not look at the sheet and read with me because of literacy issues). Further, not all participants provided thorough open-ended responses when probed to elaborate about reported barriers; in several cases this appeared to be related to the patient's desire to complete the instrument quickly.

Researchers experienced good cooperation, with $<15 \%$ of those approached declining to participate. Any initial reluctance in answering questions appeared to dissipate with time, as participants provided more details describing specific barriers as the interview progressed.

Considerably more information was obtained by asking specific questions, beyond the yield from the opening probe ("What are some of the challenges that you experience...?"). In fact, less than half (42\%) could provide a coherent open-ended answer about self-care barriers, despite all participants reporting a number of barriers when asked specific structured items. For example, one participant did not reply to the opening probe but then indicated "sometimes" or "often" experiencing 35 (74\%) of the specific barriers; he spent 45 minutes describing in depth dealing with HIV/AIDS, having his driver's license suspended, not knowing when his medications are changed or what he should be eating, being scared to take medications, not having anyone to help him, and having to stay in a homeless shelter. This and other examples of patients "opening up" illustrate the usefulness of asking specific structured probes. In contrast to the limited information obtained using the opening probe, the follow-up probes usually yielded additional information about the specific nature of the barrier that could not be learned from "often," "sometimes," or "never" responses alone (see Table 3). For example, a patient probed to elaborate on why they indicated "often" experiencing a lack of food-related resources explained that it is "more expensive to get the right foods." Occasional probes following "never" responses were also sometimes useful. For instance, one patient reported "never" having problems with knowledge about dietary self-care recommendations but went on to explain that the "real issue": between diabetic dietary restrictions, a lack of energy, and suppressed appetite, fast food and packaged products were an easy choice to make over preparing healthy food herself. 
Thirteen (42\%) patients provided information in response to the closing probe. Responses usually reemphasized a barrier that was already described, summarized their thoughts about self-care, or in a few cases provided additional detail about self-care barriers. For the 58\% who provided no response to the closing probe, it was not clear whether this was due to the exhaustive nature of the specific barrier items or participant fatigue. Examining the barriers reported in opening and closing probes only, a median of 2.5 barriers were mentioned (range 1-13), and these were mostly "person" barriers (e.g., comorbidities, functional limitations, and knowledge). The second most commonly reported unprompted barrier type was organizational issues such as financial constraints, insurance problems, and inadequate living arrangements.

Researchers reported difficulties administering the instrument due to interruptions for clinical treatment, which also produced longer instrument administration durations, and the confined and noisy environment of the ED room.

\section{LIMITATIONS}

Our instrument combined closed- and open-ended questions to take advantage of strengths and mitigate limitations of existing quantitative survey instruments and less-structured qualitative interview instruments, particularly with respect to deployment in a time-sensitive ED setting (Table 4).

We note that all but one participant was admitted to the hospital, but this was consistent with the ED's typical rate of $90 \%$ admission for AHF and with a national 5-year rate of over $80 \% .^{2}$ Because of our relatively small sample size and use of a single ED, further research will be needed to verify our findings and further test and develop the feasibility of the instrument. In light of evidence that self-care behaviors and perceptions may be culturespecific, ${ }^{60-63}$ future work should use our instrument for a cross-cultural comparison. Moreover, it is possible that patients were unable or unwilling to accurately report their selfcare barriers. Some barriers such as food culture or tool overdependence may fall outside of an individual's awareness. Others may be overly sensitive or difficult to articulate, especially in front of individuals affiliated with one's healthcare delivery system. Some of this might be alleviated by using electronic, self-administered instruments. Other methods could also be used to supplement our self-care barriers instrument. Possibilities include independent home or community assessments, mining of the EHR for information on barriers, ${ }^{64}$ or the use of geospatial information to determine a patient's or group of patients' self-care barriers. ${ }^{65}$ For example, automated geospatial analysis of food, exercise, and transportation resources near a patient's home and work could provide information without the need for patient self-report.

Additional planned analyses will address associations between reported barriers and variables such as presence of a family member, comorbidity, number of prior ED visits, prior medical history, and demographics. It also remains to be seen which barriers are correlated with others (e.g., cognitive impairment and knowledge, transportation problems and lack of caregiver). Furthermore, future tests of the instrument in practice would benefit from more formal assessments of feasibility, including costs data. 


\section{DISCUSSION}

In this study of 31 patients presenting to the ED with AHF, we piloted an instrument with both structured and open-ended items measuring the prevalence and nature of barriers to self-care. Of the 47 distinct barriers assessed, many were indicated as sometimes or often present by participants, all patients reported experiencing multiple barriers, and patients had various barrier profiles. The sources of barriers included the person, self-care tasks, tools and technologies, and organizational, social, and physical contexts. This was consistent with patient-reported barriers from Retrum et al.'s ${ }^{15}$ recent interview study which suggested that symptom severity, disease progression, mood, transportation problems, lack of food resources, cost of medications and financial stress, and inadequate access to and quality of healthcare services were reasons for heart failure patient readmission. Our study identified those and other barriers, while also providing prevalence information. It was the first study in the ED to describe the complexity of patients' self-care barriers and an important illustration of a patient-centered, sociotechnical systems-based approach to research on AHF patients in the ED.

Patients discharged from the ED or hospital following an AHF diagnosis may be clinically stable but otherwise underprepared to perform self-care recommendations such as medication self-management, diet, and symptom monitoring. ${ }^{8}$ Recognizing this, Moser et al. ${ }^{66}$ stated:

The number of psychological, social, and behavioral risk factors that challenge many patients adds substantially to the risk burden conferred by physiological factors. Depression, anxiety, poor quality of life, functional impairment, poor symptom status, suboptimal living situation, comorbidities, and poor adherence are common among discharged HF patients. Healthcare providers must develop more aggressive strategies to assess these risk factors so that they can be appropriately managed after discharge.

However, clinicians rarely assess or document the full range of risk factors or self-care barriers. One study of such barriers noted that "few charts showed evidence that the physician of record inquired in depth into patients' social support systems and postdischarge environment." 15 This underassessment that occurs in the ED is likely multifactorial. It may be impacted by the perceived time required to do this, the lack of expertise in probing patients about their barriers, and the means to address barriers that may arise during the assessment. Assessing self-care barriers in a setting such as the ED is achievable using an instrument that captures a range of relevant barriers, elicits enough information about each barrier to be able to address it appropriately, and can be completed without undue burden. We believe the first step in addressing barriers is to develop a focused, valid, and feasible measurement instrument for self-care barriers in the ED. This will facilitate not only a discussion about patient barriers, but will also inform providers about barriers that may be intervened upon during an ED visit. Addressing these barriers is a critical unmet need and is crucial to enable safe ED discharge of patients with AHF. While most of the patients in this study were not discharged from the ED or managed in an ED-based observation unit, based on prior estimates, ${ }^{8,67}$ up to $30 \%$ could have been and knowing their barriers, or lack thereof, may have informed the decision to do so and the kinds of resources that might need 
to be provided when discharged from the ED. Resources to address barriers could include changes to medications, access to medications and providers, education, and referral to social work or community safety net resources. It is important to better develop the resources and solutions, such as programs for free or reduced-price medications, transportation pools, or literacy-appropriate brochures, so that they can be matched to identified barriers.

Recent reviews of the literature demonstrate that self-care barriers are related not only to important biomedical and personal characteristics such as symptom severity, medication knowledge, and health literacy, ${ }^{12,68}$ but to factors from the broader sociotechnical system, which includes the person, their environment and healthcare system, and more. ${ }^{10,11,30,54}$ However, quantitative survey studies have typically measured only a few variables, particular quantifiable patient factors such as age, health status, illness beliefs. ${ }^{11,32}$ Prior qualitative studies using in-depth interviews have successfully identified self-care barriers from the broader system, ${ }^{28,69}$ but while these have been instructive, they have lacked systems models, consistent reporting of barrier prevalence, and barrier assessments instruments that can be feasibly implemented in the ED. In this study, measuring a wide assortment of barriers across the whole sociotechnical system, person barriers were common but so were organizational context and task barriers. Moreover, for some individuals, profound barriers from the social and physical context were found. Only tool-related barriers were infrequently reported, though only two items were used to measure these. Notably, the structured barrier items and follow-up probes yielded a larger number and bigger variety of reported barriers, compared to opening and closing probes resembling the kinds of questions asked in normal clinical practice.

Importantly, a wide array of barriers could be feasibly measured in the ED by clinicians and non-clinicians. Instrument administration time was somewhat longer and more variable than desirable, but we believe that with modification the instrument can be administered in $\leq 30$ minutes. Items may need to be eliminated or combined prior to widespread implementation. Item deletion can be guided by deploying the instrument in a sample large enough for factor analysis and reliable identification of low-frequency barriers. We believe that a variety of research or clinical staff could have administered the instrument and this should be explored in subsequent multi-center investigations. ED and inpatient settings are feasible environments for extended data collection because the instrument can be administered during waiting times. In contrast, recent work has identified numerous specific but addressable challenges for collecting self-care barriers and other data in home and community settings. ${ }^{70}$

An emerging finding is that heart failure self-care and other health-related activities are carried out in the context of a multifaceted and highly distributed self-care system. ${ }^{22,27,71}$ From a distributed cognition perspective, ${ }^{72,73}$ heart failure self-care tasks, knowledge, and expertise are distributed across people (e.g., patient, informal caregivers, physicians, nurses, community pharmacists), artifacts (e.g., weight logs, ED white board), time (e.g., days, nights, before/after meals), and space (e.g., park, kitchen, the ED, doctor's office, retail pharmacy). This implies that self-care goals are rarely achieved by a single person (e.g., the patient) or single entity (e.g., the ED) but come about through the shared awareness of plans 
and goals, a joint understanding of a situation, the collaborative and coordinated use of technology and other resources (e.g., EHR), as well as the proper arrangement of physical spaces in which self-care activities take place. ${ }^{74,75}$

It is also important to note that heart failure management is a dynamic process that involves recognition and adapting to unexpected variability and perturbations, called "resilience."76 In a resilient system, adequate decision-space, flexibility, and opportunity for collaboration must be built into its design so that local actors (e.g., patients, family, healthcare professionals) are able to manage trade-offs or derive sensible workarounds to respond to expected and unexpected goal-constraints. ${ }^{77,78}$ Self-care barriers are one of the constraints that these individuals must collaboratively and successfully manage to achieve resilience.

In conclusion, we believe not measuring and acting on self-care barriers represents a significant lost opportunity to improve care as well as decrease future ED visits and hospitalizations. ${ }^{8}$ While doing so may require an up-front investment in resources, it will have significant downstream impact and cost savings. Merely decreasing readmissions by $5 \%$ would conserve significant healthcare resources. ${ }^{8,79}$ For this and other reasons, we and others urge deeper inquiry into the contextual factors that shape the distributed and resilient health-related "work" of patients. ${ }^{24,80}$

\section{Acknowledgments}

We thank the participants in this study. We thank Emergency Medicine research staff with assistance during recruitment. This study and RJH were sponsored by grants from the National Institute on Aging (NIA) of the US National Institutes of Health (NIH) (K01AG044439) and grants UL1 TR000445 and KL2 TR000446 from the National Center for Advancing Translational Sciences (NCATS/NIH) through the Vanderbilt CTSA. ABS received grant support from NIH / NHLBI (K12HL109019) and NCATS (UL1TR000445). The content is solely the responsibility of the authors and does not necessarily represent the official views of the NIH.

\section{APPENDIX A. Self-care barriers instrument Opening probe}

A. Challenges you may experience

What are some of the challenges that you experience taking care of your health? (Challenges are things that make it harder to take good care of yourself)

\section{Structured barrier items}

B. Which of these make it harder to take good care of yourself...?

Response scale (repeated for each item):

$\square$ OFTEN $^{*} \square$ SOMETIMES* $^{*}$ NEVER ... makes it harder to take good care of myself

*If "often" or "sometimes," probe with: "Tell me more about that..." 


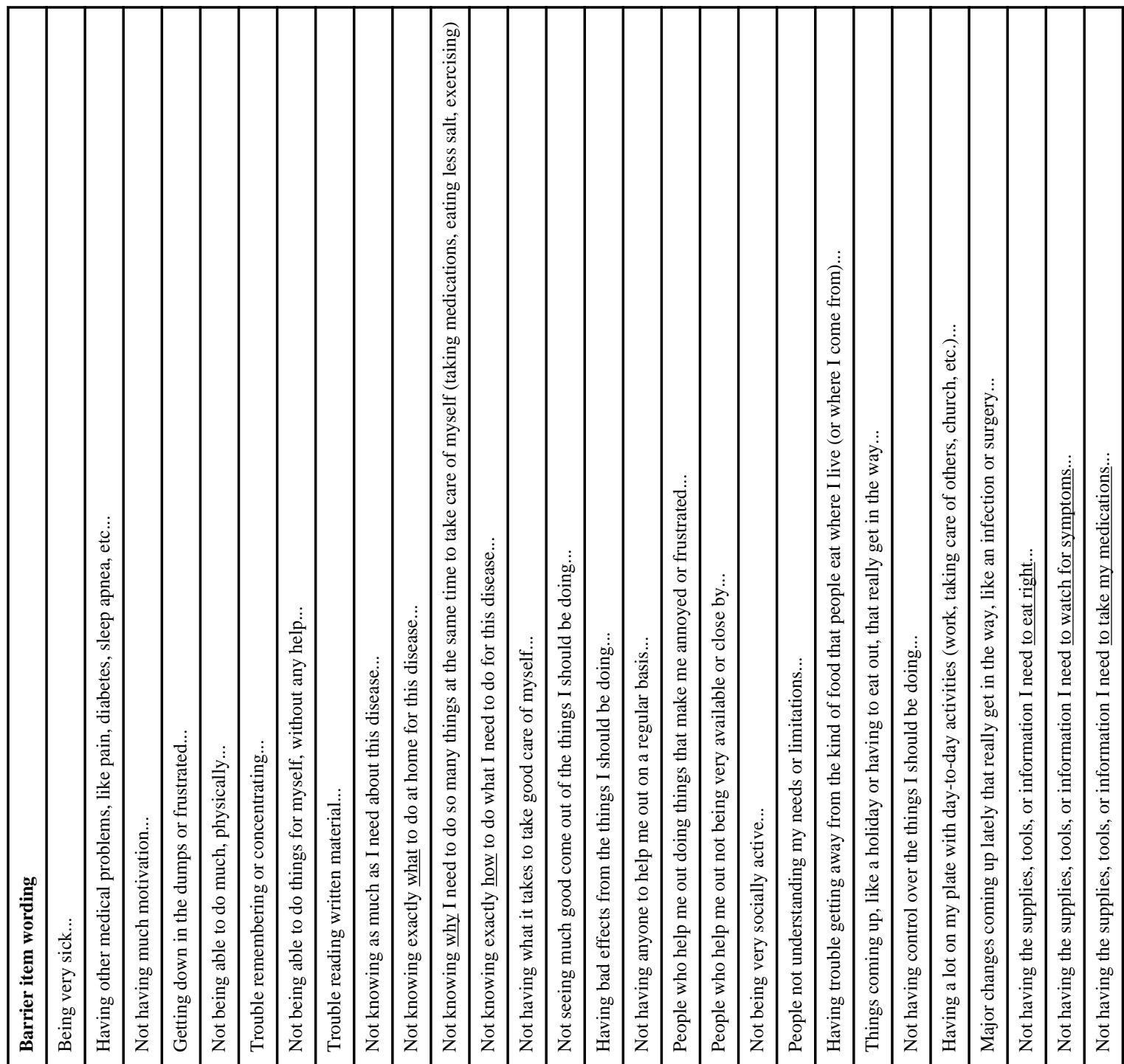





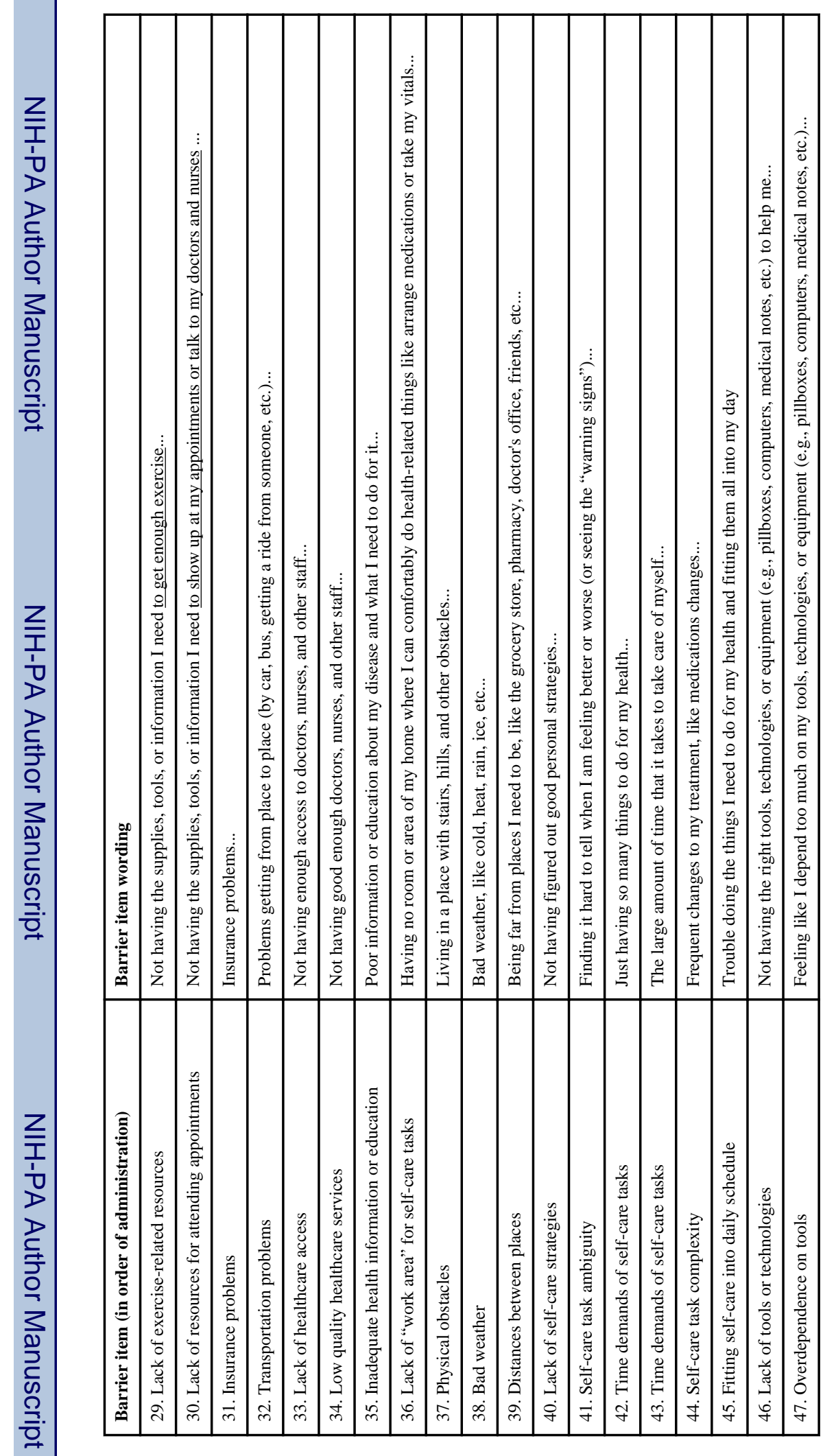

C. Which of these make it easier to take good care of yourself...? 
(Not included in current study)

\section{Closing probe}

D. Anything else?

Please tell us if there is anything that we missed that you feel is important about your selfcare.

\section{WORKS CITED}

1. Heidenreich PA, Trogdon JG, Khavjou OA, et al. Forecasting the Future of Cardiovascular Disease in the United States. Circulation. March 1.2011 123:933-944. 2011. [PubMed: 21262990]

2. Storrow AB, Jenkins CA, Self WH, et al. The Burden of Acute Heart Failure on U.S. Emergency Departments. JACC: Heart Failure. 2014; 2(3):269-277. [PubMed: 24952694]

3. Adams KF Jr. Fonarow GC, Emerman CL, et al. Characteristics and outcomes of patients hospitalized for heart failure in the United States: rationale, design, and preliminary observations from the first 100,000 cases in the Acute Decompensated Heart Failure National Registry (ADHERE). Am Heart J. Feb; 2005 149(2):209-216. [PubMed: 15846257]

4. Lloyd-Jones D, Adams RJ, Brown TM, et al. Heart disease and stroke statistics--2010 update: a report from the American Heart Association. Circulation. Feb 23; 2010 121(7):e46-e215. [PubMed: 20019324]

5. Jencks SF, Williams MV, Coleman EA. Rehospitalizations among patients in the Medicare fee-forservice program. N Engl J Med. Apr 2; 2009 360(14):1418-1428. [PubMed: 19339721]

6. Dharmarajan K, Hsieh AF, Lin Z, et al. Diagnoses and timing of 30-day readmissions after hospitalization for heart failure, acute myocardial infarction, or pneumonia. JAMA. Jan 23; 2013 309(4):355-363. [PubMed: 23340637]

7. Marti CN, Georgiopoulou VV, Giamouzis G, et al. Patient-reported selective adherence to heart failure self-care recommendations: a prospective cohort study: the Atlanta Cardiomyopathy Consortium. Congestive Heart Failure. Jan-Feb.2013 19:16-24. [PubMed: 22958604]

8. Collins SP, Storrow AB. Moving toward comprehensive acute heart failure risk assessment in the emergency department. Journal of the American College of Cardiology: Heart Failure. 2013; 1:274280.

9. Riegel B, Lee CS, Dickson VV. Self care in patients with chronic heart failure. Nat Rev Cardiol. 2011; 8:644-654. [PubMed: 21769111]

10. McEntee ML, Cuomo LR, Dennison CR. Patient-, provider-, and system-level barriers to heart failure care. J Cardiovasc Nurs. 2009; 24(4):290-298. [PubMed: 19465864]

11. Oosterom-Calo R, van Ballegooijen AJ, Terwee CB, et al. Determinants of heart failure self-care: A systematic literature review. Heart Failure Reviews. 2012; 17:367-385. [PubMed: 22134397]

12. Hope CJ, Wu J, Tu W, et al. Association of medication adherence, knowledge, and skills with emergency department visits by adults 50 years or older with congestive heart failure. Am J Health Syst Pharm. 2004; 61:2043-2049. [PubMed: 15509127]

13. Welsh JD, Heiser RM, Schooler MP, et al. Characteristics and treatment of patients with heart failure in the emergency department. Journal of Emergency Nursing. 2002; 28:126-131. [PubMed: 11960124]

14. Bazargan-Hejazi S, Bazargan M, Hardin E, et al. Alcohol use and adherence to prescribed therapy among under-served Latino and African-American patients using emergency department services. Ethnicity \& Disease. 2005; 15:267-275.

15. Retrum JH, Boggs J, Hersh A, et al. Patient-identified factors related to heart failure readmissions. Circulation: Cardiovascular Quality and Outcomes. 2013; 6:171-177.

16. Karsh B, Holden RJ, Alper SJ, et al. A human factors engineering paradigm for patient safety designing to support the performance of the health care professional. Qual Saf Health Care. 2006; 15:i59-i65. [PubMed: 17142611] 
17. Russ AL, Fairbanks RJ, Karsh B, et al. The science of human factors: Separating fact from fiction. BMJ Qual Saf. 2013 forthcoming, http://dx.doi.org/10.1136/bmjqs-2012-002036. [PubMed: 23592760]

18. Schubert CC, Denmark TK, Crandall B, et al. Characterizing novice-expert differences in macrocognition: an exploratory study of cognitive work in the emergency department. Ann Emerg Med. 2013; 61:96-109. [PubMed: 23036439]

19. Wears RL, Perry SJ. Human factors and ergonomics in the emergency department. Ann Emerg Med. 40(2):206-212. [PubMed: 12140500]

20. Holden RJ. Lean thinking in emergency departments: A critical review. Ann Emerg Med. 2011; 57:265-278. [PubMed: 21035904]

21. Fairbanks RJ, Bisantz AM, Sunm M. Emergency Department Communication Links and Patterns. Ann Emerg Med. 50(4):396-406. 10//2007. [PubMed: 17559973]

22. Schubert, CC.; Wears, RL.; Holden, RJ., et al. Patients as source of resilience.. In: Wears, RL.; Hollnagel, E.; Braithwaite, J., editors. Resilience of Everyday Clinical Work. Ashgate; Aldershot, $\mathrm{UK}$ : in press

23. Holden RJ, Carayon P, Gurses AP, et al. SEIPS 2.0: A human factors framework for studying and improving the work of healthcare professionals and patients. Ergonomics. 2013; 56(11):16691686. [PubMed: 24088063]

24. Valdez RS, Holden RJ, Novak LL, et al. Transforming consumer health informatics through a patient work framework: Connecting patients to context. J Am Med Inform Assoc. in press:doi: 10.1136/amiajnl-2014-002826. [PubMed: 25125685]

25. Carayon P, Schoofs Hundt A, Karsh B, et al. Work system design for patient safety: the SEIPS model. Qual Saf Health Care. 2006; 15:i50-i58. [PubMed: 17142610]

26. Holden RJ, Mickelson RS. Performance barriers among elderly chronic heart failure patients: An application of patient-engaged human factors and ergonomics. Proceedings of the Human Factors and Ergonomics Society. 2013; 57(1):758-762.

27. Holden RJ, Schubert CC, Mickelson RS. The patient work system: An analysis of self-care performance barriers among elderly heart failure patients and their informal caregivers. Appl Ergon. 2015; 47:133-150. [PubMed: 25479983]

28. Clark AM, Spaling M, Harkness K, et al. Determinants of effective heart failure self-care: A systematic review of patients' and caregivers' perceptions. Heart. in press:doi:10.1136/ heartjnl-2013-304852. [PubMed: 24548920]

29. Wu J-R, Moser DK, Lennie TA, et al. Medication adherence in patients who have heart failure: A review of the literature. Nurs Clin N Am. 2008; 43:133-153.

30. Oosterom-Calo R, van Ballegooijen AJ, Terwee CB, et al. Determinants of adherence to heart failure medication: A systematic literature review. Heart Failure Reviews. 2013; 18:409-427. [PubMed: 22723048]

31. Anderson MA, Levsen J, Dusio ME, et al. Evidenced-based factors in readmission of patients with heart failure. J Nurs Care Qual. Apr-Jun; 2006 21(2):160-167. [PubMed: 16540785]

32. Albert NM, Levy P, Langlois E, et al. Heart failure beliefs and self-care adherence while being treated in an emergency department. Journal of Emergency Medicine. 2014; 46:122-129. [PubMed: 24054880]

33. Cheng JK. Confronting the social determinants of health--obesity, neglect, and inequity. N Engl J Med. Nov 22; 2012 367(21):1976-1977. [PubMed: 23171094]

34. Weiner SJ, Schwartz A, Weaver F, et al. Contextual errors and failures in individualizing patient care: a multicenter study. Ann Intern Med. Jul 20; 2010 153(2):69-75. [PubMed: 20643988]

35. Weiner SJ, Schwartz A, Sharma G, et al. Patient-centered decision making and health care outcomes: an observational study. Ann Intern Med. Apr 16; 2013 158(8):573-579. [PubMed: 23588745]

36. Capturing Social and Behavioral Domains in Electronic Health Records: Phase 1. National Academies Press; Washington (DC): 2014. Institute of Medicine - Committee on the Recommended Social and Behavioral Domains and Measures for Electronic Health Records.. 
37. Capturing Social and Behavioral Domains in Electronic Health Records: Phase 2. National Academies Press; Washington (DC): 2014. Institute of Medicine - Committee on the Recommended Social and Behavioral Domains and Measures for Electronic Health Records..

38. Jessup M, Abraham WT, Casey DE, et al. 2009 Focused Update: ACCF/AHA Guidelines for the Diagnosis and Management of Heart Failure in Adults. Circulation. April 14.2009 119:1977-2016. 2009. [PubMed: 19324967]

39. Riegel B, Moser DK, Anker SD, et al. State of the science: Promoting self-care in persons with heart failure: A scientific statement from the American Heart Association. Circulation. September 22.2009 120:1141-1163. 2009. [PubMed: 19720935]

40. Lainscak M, Blue L, Clark AL, et al. Self-care management of heart failure: practical recommendations from the Patient Care Committee of the Heart Failure Association of the European Society of Cardiology. Eur J Heart Fail. February 1.2011 13:115-126. 2011. [PubMed: 21148593]

41. Dickstein K, Vardas PE, Auricchio A, et al. 2010 Focused Update of ESC Guidelines on device therapy in heart failure: an update of the 2008 ESC Guidelines for the diagnosis and treatment of acute and chronic heart failure and the 2007 ESC guidelines for cardiac and resynchronization therapy. Developed with the special contribution of the Heart Failure Association and the European Heart Rhythm Association. Eur Heart J. Nov. 2010; 31(21):2677-2687.

42. Heart Failure Society Of A. Nonpharmacologic management and health care maintenance in patients with chronic heart failure. J Card Fail. Feb; 2006 12(1):e29-37. [PubMed: 16500569]

43. van der Wal MHL, Jaarsma T. Adherence in heart failure in the elderly: Problem and possible solutions. Int J Cardiol. 2008; 125:203-208. [PubMed: 18031843]

44. Tao H, Ellenbecker CH, Chen J, et al. The influence of social environmental factors on rehospitalization among patients receiving home health care services. ANS. Advances in nursing science. Oct-Dec; 2012 35(4):346-358. [PubMed: 23107991]

45. van der Wal MH, Jaarsma T, Moser DK, et al. Qualitative examination of compliance in heart failure patients in The Netherlands. Heart Lung. 2010; 39:121-130. [PubMed: 20207272]

46. Riegel B, Carlson B. Facilitators and barriers to heart failure self-care. Patient Educ Couns. 2002; 46(4):287-295. [PubMed: 11932128]

47. Jovicic A, Holroyd-Leduc JM, Straus SE. Effects of self-management intervention on health outcomes of patients with heart failure: a systematic review of randomized controlled trials. BMC Cardiovasc Disord. 2006; 6:43. [PubMed: 17081306]

48. Lennie TA, Worrall-Carter L, Hammash M, et al. Relationship of heart failure patients' knowledge, perceived barriers, and attitudes regarding low-sodium diet recommendations to adherence. Progress in cardiovascular nursing. 2008; 23(1):6-11. Winter. [PubMed: 18326994]

49. Barnason S, Zimmerman L, Young L. An integrative review of interventions promoting self-care of patients with heart failure. J Clin Nurs. Feb; 2012 21(3-4):448-475. [PubMed: 22098479]

50. Simpson SH, Farris KB, Johnson JA, et al. Using focus groups to identify barriers to drug use in patients with congestive heart failure. Pharmacotherapy. 2000; 20:823-829. [PubMed: 10907972]

51. Simpson SH, Johnson JA, Farris KB, et al. Development and validation of a survey to assess barriers to drug use in patients with chronic heart failure. Pharmacotherapy. Sep; 2002 22(9): 1163-1172. [PubMed: 12222552]

52. Knight DA, Thompson D, Mathie E, et al. 'Seamless care? Just a list would have helped!' Older people and their carer's experiences of support with medication on discharge home from hospital. Health Expect. Sep; 2013 16(3):277-291. [PubMed: 21838834]

53. Arbaje AI, Wolff JL, Yu Q, et al. Postdischarge environmental and socioeconomic factors and the likelihood of early hospital readmission among community-dwelling medicare beneficiaries. The Gerontologist. 2008; 48:495-504. [PubMed: 18728299]

54. Wu JR, Moser DK, Chung ML, et al. Predictors of medication adherence using a multidimensional adherence model in patients with heart failure. J Card Fail. Sep; 2008 14(7):603-614. [PubMed: 18722327]

55. Riegel B, Dickson VV, Kuhn L, et al. Gender-specific barriers and facilitators to heart failure selfcare: a mixed methods study. Int J Nurs Stud. Jul; 2010 47(7):888-895. [PubMed: 20079902] 
56. Rohrmann, B. Verbal qualifiers for rating scales: Sociolinguistic considerations and psychometric data. University of Melbourne; Australia: 2007.

57. Edelen MO, Reeve BB. Applying item response theory (IRT) modeling to questionnaire development, evaluation, and refinement. Quality of Life Research. 2007; 16:5-18. [PubMed: 17375372]

58. Sandelowski M. Whatever happened to qualitative description? Res Nurs Health. 2000; 23:334340. [PubMed: 10940958]

59. Hsieh H-F, Shannon SE. Three approaches to qualitative content analysis. Qualitative Health Research. 2005; 15:1277-1288. [PubMed: 16204405]

60. Jang Y, Toth J, Yoo H. Similarities and Differences of Self-Care Behaviors Between Korean Americans and Caucasian Americans With Heart Failure. Journal of Transcultural Nursing. July 1; 2012 23(3):246-254. 2012. [PubMed: 22477714]

61. Smith SL, Quandt SA, Arcury TA, et al. Aging and eating in the rural, southern United States: Beliefs about salt and its effect on health. Soc Sci Med. 2006; 62:189-198. [PubMed: 15990209]

62. Lip GYH, Khan H, Bhatnagar A, et al. Ethnic differences in patient perceptions of heart failure and treatment: the West Birmingham heart failure project. Heart. 2004; 90:1016-1019. [PubMed: 15310689]

63. Tirodkar MA, Baker DW, Khurana N, et al. Explanatory models of coronary heart disease among South Asian immigrants. Patient Educ Couns. Nov; 2011 85(2):230-236. [PubMed: 21093195]

64. Weiner SJ, Kelly B, Ashley N, et al. Content coding for contextualization of care: evaluating physician performance at patient-centered decision making. Medical decision making : an international journal of the Society for Medical Decision Making. Jan; 2014 34(1):97-106.

65. Bryce SN, Storrow AB, Miller KF, et al. Optimizing self-care skills for patients with acute heart failure using geospatial analysis. Ann Emerg Med. 2013; 62(4):S157.

66. Moser DK, Doering LV, Chung ML. Vulnerabilities of patients recovering from an exacerbation of chronic heart failure. Am Heart J. 2005; 150:984.e987-984.e913.

67. Collins S, Storrow AB, Albert NM, et al. Early Management of Patients With Acute Heart Failure: State of the Art and Future Directions. A Consensus Document From the Society for Academic Emergency Medicine/Heart Failure Society of America Acute Heart Failure Working Group. J Card Fail. Jul 18.2014 [PubMed: 25042620]

68. Anderson KM. Discharge clinical characteristics and 60-day readmission in patients hospitalized with heart failure. J Cardiovasc Nurs. 2014; 29(3):232-241. [PubMed: 23612038]

69. Siabani, S.; Leeder, SR.; Davidson, PM. Barriers and facilitators to self-care in chronic heart failure: a meta-synthesis of qualitative studies.; Springerplus. 2013. p. 2http:// www.springerplus.com/content/2/1/320

70. Holden RJ, McDougald Scott AM, Hoonakker PLT, et al. Data collection challenges in community settings: Insights from two field studies of patients with chronic disease. Quality of Life Research. in press:DOI: 10.1007/s11136-11014-10780-y. [PubMed: 25154464]

71. Mickelson RS, Holden RJ. Assessing the distributed nature of home-based heart failure medication management in older adults. Proceedings of the Human Factors and Ergonomics Society. 2013; 57(1):753-757.

72. Hutchins, E. Cognition in the Wild. MIT Press; Cambridge, MA: 1995.

73. Perry, M. Proceedings of the European Conference on Cognitive Science. Siena, Italy: 1999. The application of individually and socially distributed cognition in workplace studies: two peas in a pod?; p. 87-92.

74. Strachan, PH. Mrs. Jones can't breathe: Can a resilience framework help?. In: Hollnagel, E.; Braithwaite, J.; Wears, RL., editors. Resilient Health Care. Ashgate; Burlington, VT: 2013. p. 215-225.

75. Artman H, Waern Y. Distributed cognition in an emergency co-ordination center. Cogn Technol Work. 1999; 1:237-246.

76. Woods, DD. Essential characteristics of resilience.. In: Hollnagel, E.; Woods, DD.; Leveson, N., editors. Resilience Engineering: Concepts and Precepts. Ashgate; Aldershot, UK: 2006. p. 21-34.

77. Hoffman RR, Woods DD. Simon's slice: Five fundamental tradeoffs that bound the performance of macrocognitive work systems. IEEE Intell Syst. 2011; 26(6):67-71. 
78. Wears, RL.; Schubert, CC.; Hunte, GS. Individual-collective trade-offs: Implications for resilience.. In: Wears, RL.; Hollnagel, E.; Braithwaite, J., editors. Resilience of everyday clinical work. Ashgate; Aldershot, UK: in press

79. Collins SP, Pang PS, Fonarow GC, et al. Is hospital admission for heart failure really necessary?: the role of the emergency department and observation unit in preventing hospitalization and rehospitalization. J Am Coll Cardiol. Jan 15; 2013 61(2):121-126. [PubMed: 23273288]

80. Granger BB, Moser D, Harrell J, et al. A practical use of theory to study adherence. Progress in cardiovascular nursing. 2007; 22(3):152-158. [PubMed: 17786091] 


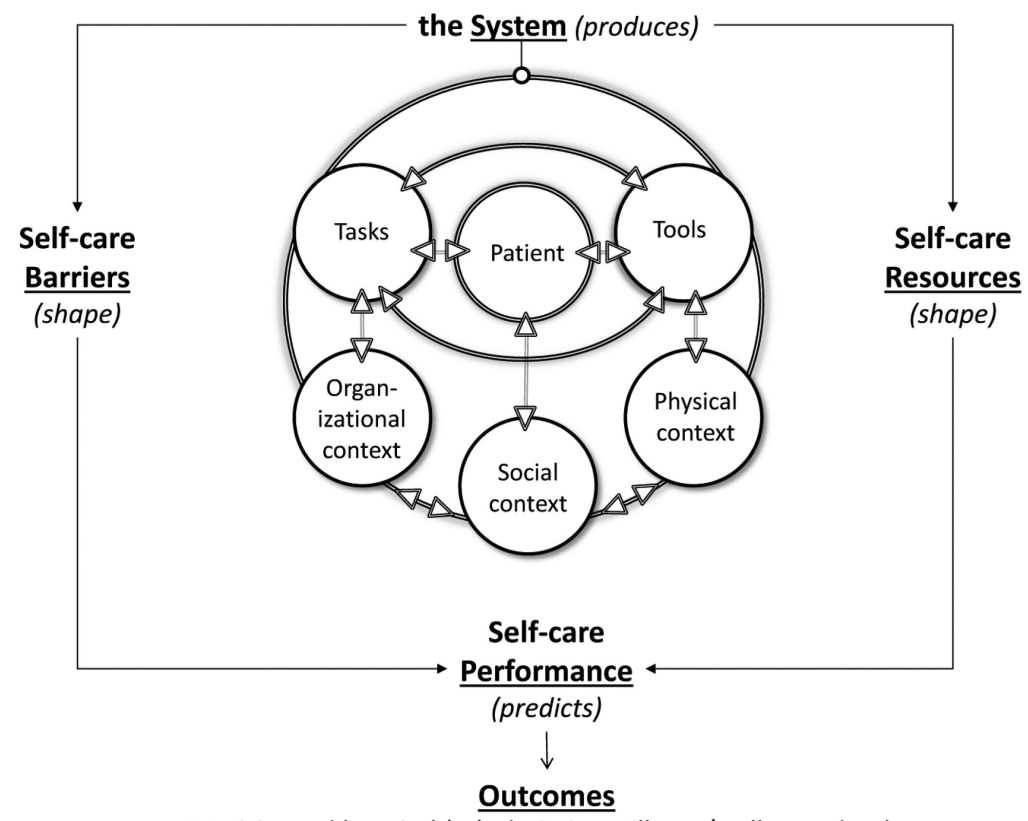

ED visits and hospital (re)admissions, illness/wellness, death

Figure 1.

A sociotechnical systems model of self-care barriers (and resources). 


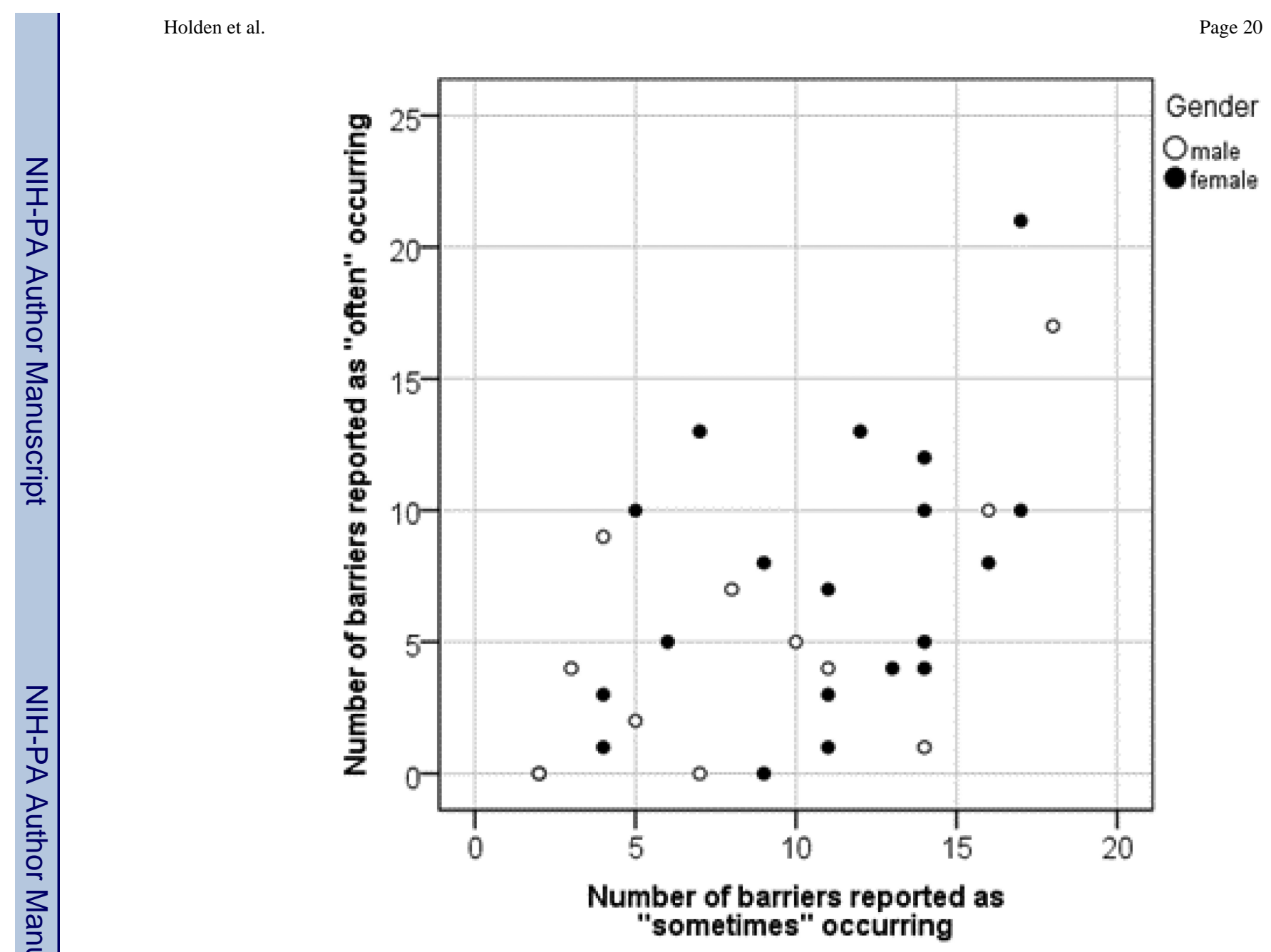

Figure 2.

Distribution of participants reporting barriers occurring "sometimes" vs. "often." 


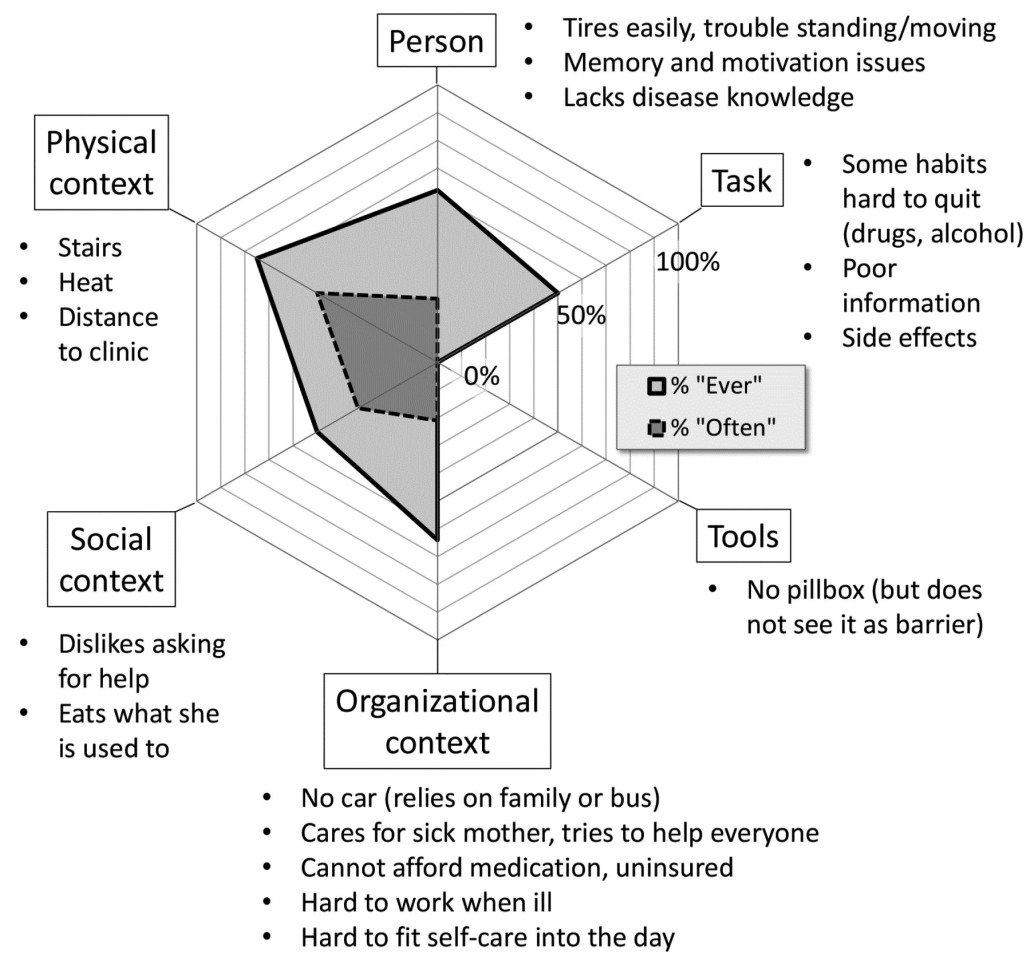

Figure 3.

A barrier profile, showing the barriers reported by an uninsured (self-pay) 52 year-old black female, employed full time, with a tenth grade education and recent incarceration. The plot represents the percentage of items per system category that the patient indicated as "often" or "ever" a barrier to self-care. Bulleted items are taken from responses to open-ended probes. 
Table 1

Patient demographic and medical information

\begin{tabular}{|l|l|}
\hline Age, median (range) & $69(29-91)$ \\
\hline Sex & 19 female (61\%), 12 male (39\%) \\
\hline \multirow{2}{*}{ Race } & 21 White/Caucasian (68\%) \\
\cline { 2 - 2 } & 10 Black/African American (32\%) \\
\hline Hypertension & 11 retired (35\%), 11 disabled (35\%), 4 unemployed (13\%) \\
\cline { 2 - 2 } & 4 full-time (13\%), 1 part-time (3\%) \\
\hline Diabetes mellitus & $23(74 \%)$ \\
\hline Renal disease & $15(48 \%)$ \\
\hline Prior myocardial infarction & $13(42 \%)$ \\
\hline Prior heart failure diagnosis & $31(19 \%)$ \\
\hline Laboratory tests, median (range) & \\
\hline BNP (n=30) (pg/ml) & $557.5(64-5065)$ \\
\hline BUN (n=30) (mg/dl) & $21.5(8-66)$ \\
\hline Cr (mg/dl) & $1.30(0.78-3.21)$ \\
\hline Hgb (gm/dl) & $11.9(7.6-15.1)$ \\
\hline Na $2+(m m o l / L)$ & $139(119-142)$ \\
\hline
\end{tabular}

$\mathrm{BNP}=\mathrm{B}$-type natriuretic peptide, $\mathrm{BUN}=\mathrm{Blood}$ urea nitrogen, $\mathrm{Cr}=\mathrm{Creatinine}, \mathrm{Hgb}=\mathrm{Hemoglobin}, \mathrm{Na}^{2+}=$ serum sodium 
Table 2

Self-care barriers, in order of prevalence.

\begin{tabular}{|c|c|c|c|c|}
\hline Self-care barrier type & \% "Ever", a,b & $\%$ "Often", & \% "Sometimes" & System category \\
\hline 1. Comorbidities & 74.2 & 38.7 & 35.5 & PT \\
\hline 2. Physical disability & 71.0 & 35.5 & 35.5 & PT \\
\hline 3. Degree of sickness & 70.0 & 46.7 & 23.3 & PT \\
\hline 4. Feeling frustrated & 64.6 & 19.4 & 45.2 & PT \\
\hline 5. Knowledge about disease & 64.5 & 25.8 & 38.7 & PT \\
\hline 6. Functional limitations & 58.0 & 16.1 & 41.9 & PT \\
\hline 7. Memory and attention deficits & 54.9 & 19.4 & 35.5 & PT \\
\hline 8. Special occasions (minor disruptions) & 51.6 & 22.6 & 29 & ORG \\
\hline 9. Lack of control & 51.6 & 16.1 & 35.5 & ORG \\
\hline 10. Disruptions (major disruptions) & 46.6 & 13.3 & 33.3 & ORG \\
\hline 11. Knowledge about self-care & 45.2 & 22.6 & 22.6 & PT \\
\hline 12. Lack of motivation & 43.3 & 13.3 & 30.0 & PT \\
\hline 13. Inadequate health information or education & 42.0 & 6.5 & 35.5 & TASK \\
\hline 14. Self-care task complexity & 41.9 & 25.8 & 16.1 & TASK \\
\hline 15. Bad weather & 41.9 & 16.1 & 25.8 & PHYS \\
\hline 16. Food culture & 38.8 & 19.4 & 19.4 & SOC \\
\hline 17. Time demands of self-care tasks & 36.7 & 16.7 & 20 & TASK \\
\hline 18. Lack of exercise-related resources & 36.7 & 16.7 & 20 & ORG \\
\hline 19. Physical obstacles & 35.5 & 22.6 & 12.9 & PHYS \\
\hline 20. Low literacy & 35.5 & 16.1 & 19.4 & PT \\
\hline 21. Social inactivity & 35.5 & 16.1 & 19.4 & SOC \\
\hline 22. Lack of perceived benefit of self-care & 35.5 & 9.7 & 25.8 & TASK \\
\hline 23. Knowledge about how to carry out self-care & 35.5 & 9.7 & 25.8 & PT \\
\hline 24. Lack of symptom monitoring-related resources & 32.3 & 12.9 & 19.4 & ORG \\
\hline 25. Others do not understand my needs/limits & 32.3 & 9.7 & 22.6 & SOC \\
\hline 26. Knowledge about purpose of self-care & 32.2 & 16.1 & 16.1 & PT \\
\hline 27. Self-care task ambiguity & 32.2 & 3.2 & 29.0 & TASK \\
\hline 28. Fitting self-care into daily schedule & 30.7 & 3.8 & 26.9 & ORG \\
\hline 29. Insurance problems & 29.7 & 16.7 & 13.0 & ORG \\
\hline 30. Lack of food-related resources & 29.1 & 19.4 & 9.7 & ORG \\
\hline 31. Other life demands (e.g., work, caregiving for others) & 29.0 & 12.9 & 16.1 & ORG \\
\hline 32. Lack of self-efficacy & 29.0 & 12.9 & 16.1 & PT \\
\hline 33. Problems with caregiver & 29.0 & 12.9 & 16.1 & SOC \\
\hline 34. Perceived side-effects of self-care & 25.8 & 9.7 & 16.1 & TASK \\
\hline 35. Lack of medication-related resources & 22.6 & 6.5 & 16.1 & ORG \\
\hline 36. Lack of healthcare access & 22.6 & 6.5 & 16.1 & ORG \\
\hline
\end{tabular}




\begin{tabular}{|l|c|c|c|c|}
\hline Self-care barrier type & \% "Ever" $\boldsymbol{a}, \boldsymbol{b}$ & \% “Often" & \% "Sometimes" $\boldsymbol{b}$ & System category \\
\hline 37. Lack of caregiver & 19.4 & 6.5 & 12.9 & SOC \\
\hline 38. Lack of self-care strategies & 19.4 & 0.0 & 19.4 & TASK \\
\hline 39. Lack of tools or technologies & 19.4 & 0.0 & 19.4 & TOOL \\
\hline 40. Frequent treatment changes & 19.3 & 3.2 & 16.1 & TASK \\
\hline 41. Transportation problems & 19.3 & 3.2 & 16.1 & ORG \\
\hline 42. Distances between places & 16.2 & 9.7 & 6.5 & PHYS \\
\hline 43. Caregiver unavailability & 12.9 & 6.5 & 6.5 & SOC \\
\hline 44. Lack of resources for attending appointments & 12.9 & 0.0 & 0.0 & ORG \\
\hline 45. Low quality healthcare services & 9.7 & 3.2 & 6.5 & ORG \\
\hline 46. Overdependence on tools & 6.5 & 0.0 & 6.5 & TOOL \\
\hline 47. Lack of "work area" for self-care tasks & 0.0 & 0.0 & 0.0 & PHYS \\
\hline
\end{tabular}

$\mathrm{PT}=$ patient, $\mathrm{ORG}=$ organizational context, $\mathrm{SOC}=$ social context, $\mathrm{PHYS}=$ physical context

a Percent reporting "sometimes" or "often;"

${ }^{b}$ Calculated based on number of valid responses. 
Table 3

Examples of self-care barriers described by participants

\begin{tabular}{|c|c|}
\hline Barrier type & Examples \\
\hline Patient & $\begin{array}{l}\text { - Comorbidities: High blood pressure, arthritis, broken ankles, diabetes, right leg swollen and painful, HIV/AIDS, } \\
\text { back pain, gastroparesis } \\
\text { - Functional limitations: Difficult to lift or "do anything fast," trouble standing, cannot walk from room to room, } \\
\text { cannot read fine-print due to vision problems } \\
\text { - Mood/Frustration: Lonely with no one around, diabetes gets me down, frustrated not being able to work, some } \\
\text { good days but often very bad days and frequent nightmares } \\
\text { - Knowledge about the disease/self-care: Unaware of health risks of overexertion, does not understand why taking } \\
\text { Lasix helps and how it impacts life, does not know how often she can exercise } \\
\text { - Memory/attention: Forgets doctor's appointments and taking medications }\end{array}$ \\
\hline Tasks & $\begin{array}{l}\text { - Self-care side-effects: Exercise causes pain, thirstiness is an issue, medication side effects such as numbness in the } \\
\text { extremities } \\
\text { - Self-care complexity: Combination of diabetes and heart failure produce complex self-care, multiple demands } \\
\text { (medications, checking blood sugar), and perceived conflicts ("I didn't take my Coreg, because I thought I would } \\
\text { take care of my diabetes first") } \\
\text { - Time demands of self-care: Self-care takes a long time, no time in the day to take care of medical problems } \\
\text { because of busy schedule, morning routine "takes forever" } \\
\text { - Lack of perceived benefit of self-care: Does not see value of taking diuretic, does not perceive signs of "recovery" } \\
\text { despite being adherent to medications } \\
\text { - Self-care task ambiguity: Sudden and overwhelming symptom onset, harder to distinguish symptoms when feeling } \\
\text { down or tired }\end{array}$ \\
\hline Tools & $\begin{array}{l}\text { - Tool access and availability: No medical notes to look at or a list to take home, no computer because illiterate, no } \\
\text { internet for computer, no equipment (blood pressure cuff, diabetes test strips) }\end{array}$ \\
\hline \multirow[t]{2}{*}{ Organizational context } & $\begin{array}{l}\text { - Lack of resources: Earns less pay because cannot perform work duties (construction), cannot afford housing or } \\
\text { healthcare, co-pays are problematic, therapies are costly, chooses which prescriptions to fill due to fixed income } \\
\text { - Transportation problems: Cannot drive for past two years, cannot go where wants (to doctor, store, friends, } \\
\text { movies), need to arrange for transport to pick up prescriptions (if prescription not ready, returning is a problem), } \\
\text { cannot get to grocery store }\end{array}$ \\
\hline & $\begin{array}{l}\text { - Disruptions: Believes a little "cheating" is OK, holidays promote unhealthy diet ("Thanksgiving is a challenge"), } \\
\text { going out with others becomes "celebration time" } \\
\text { - Insurance problems: No insurance, did not have insurance due to pre-existing conditions, co-pays and premiums } \\
\text { are high }\end{array}$ \\
\hline Social context & $\begin{array}{l}\text { - Food culture: Eats kids' leftovers, hard to follow low-sodium diet when wife does not } \\
\text { - Social inactivity: No friends, no opportunity to see friends, stays at home, embarrassed to be in public when sick, } \\
\text { does not want to be a burden on others } \\
\text { - Other life demands: Overdoes things at home ("always something to do"), takes care of invalid husband and sick } \\
\text { brother. } \\
\text { - Problems with caregivers: Family rarely helps, mother can be frustrating, frustrated by daughter's attempt to help } \\
\text { ("they don't know how to do things the way I do"), family and friends not nearby or are busy, no one to help out }\end{array}$ \\
\hline Physical context & $\begin{array}{l}\text { - Weather: Heat, humidity, gets sick when it is cold, neuropathy worse when hot or cold } \\
\text { - Living in a place with stairs: Fifteen steps to front door, four steps from garage, front steps uneven, bedroom is } \\
\text { upstairs } \\
\text { - Distance between places: Cardiologist and hospital are an hour away }\end{array}$ \\
\hline
\end{tabular}


Table 4

Comparison of standardized survey, interview, and hybrid questionnaire methods for collecting self-care barrier data in the emergency department (ED).

\begin{tabular}{|c|c|c|c|}
\hline $\begin{array}{l}\text { Self-care barrier } \\
\text { collection method }\end{array}$ & Objective & Strengths & Limitations \\
\hline $\begin{array}{l}\text { Standardized survey } \\
\text { questionnaire } \\
\text { (quantitative). }\end{array}$ & $\begin{array}{l}\text { - Assess the presence and } \\
\text { prevalence of specified } \\
\text { barriers. }\end{array}$ & $\begin{array}{l}\text { - Relatively easy to administer and analyze. } \\
\text { - Easily replicable, comparable across } \\
\text { studies. } \\
\text { - Can be employed in time-sensitive ED } \\
\text { setting. }\end{array}$ & $\begin{array}{l}\text { - Lacks rich data on nature of barriers. } \\
\text { - Limited in scope to only pre- } \\
\text { specified barriers. }\end{array}$ \\
\hline $\begin{array}{l}\text { Unstructured and } \\
\text { semi-structured } \\
\text { interviews } \\
\text { (qualitative). }\end{array}$ & $\begin{array}{l}\text { - Assess the nature of a } \\
\text { wide range of unspecified } \\
\text { barriers. }\end{array}$ & $\begin{array}{l}\text { - Permits deeper, more contextual } \\
\text { understanding. } \\
\text { - Describes a wider range of barriers. }\end{array}$ & $\begin{array}{l}\text { - Resource and time intensive. } \\
\text { - Instruments vary across studies; may } \\
\text { not be comparable or replicable. } \\
\text { - Difficult to employ in time-sensitive } \\
\text { ED setting. }\end{array}$ \\
\hline $\begin{array}{l}\text { Hybrid standardized } \\
\text { questionnaire with } \\
\text { open-ended probes } \\
\text { (mixed). }\end{array}$ & $\begin{array}{l}\text { - Assess the prevalence } \\
\text { and nature of a wide } \\
\text { range of specified and } \\
\text { unspecified barriers. }\end{array}$ & $\begin{array}{l}\text { - Captures contextual understanding and } \\
\text { permits deeper inquiry per barrier. } \\
\text { - Moderately easy to administer in time- } \\
\text { sensitive ED setting. } \\
\text { - Captures most complete and systematic } \\
\text { array of barriers. } \\
\text { - Can be standardized, replicated, and } \\
\text { compared across studies. }\end{array}$ & $\begin{array}{l}\text { - In some cases requires }>30 \text { minutes } \\
\text { for administration. } \\
\text { - New instrument requires further pilot } \\
\text { testing and refinement. }\end{array}$ \\
\hline
\end{tabular}

